\title{
Idiopathic macular telangiectasia type 3
}

INSERM

\section{Source}

INSERM. (1999). Orphanet: an online rare disease and orphan drug data base. Idiopathic macular telangiectasia type 3. ORPHA:353351

Idiopathic macular telangiectasia type 3 is a rare, acquired, eye disease characterized by progressive visual loss, due to bilateral juxtafoveolar capillary occlusions, capillary telangiectasia, and minimal exudation. It is associated with systemic or cerebral vascular occlusive disease. 